\title{
The Structure and Growth Processes of Caudal Thorns
}

\author{
M. J. Gallagher ${ }^{1}$, C. P. Nolan, and F. Jeal \\ Zoology Department, Trinity College, Dublin 2, Ireland
}

Gallagher, M. J., C. P. Nolan, and F. Jeal. 2005. The Structure and Growth Processes of Caudal Thorns. J. Northw. Atl. Fish. Sci., 35: 125-129. doi:10.2960/J.v35.m529

\begin{abstract}
Caudal thorns from bathyrajids (family Rajidae), for which surface band patterns have previously been correlated with an annual cycle of vertebral band deposition, were examined to ascertain the underlying growth band structure with a view to understanding their growth processes. Caudal thorn samples from Bathyraja brachyurops, a commercial ray species from the Falkland Islands were sectioned transversely using both resin embedding and decalcification/wax embedding procedures. Sectioning revealed that internal bands formed as a series of cones underlying each other, and that broad surface bands formed annually during periods of rapid somatic growth. Surface ridges representing a near stasis in somatic growth formed at the periphery of each cone. This proposed growth process was further verified by the incorporation of tetracycline at the periphery of caudal thorns from a tagrecaptured bathyrajid. The benefits of using sectioning to enhance band resolution of larger specimens of slower growing species, particularly in the case of worn and tightly spaced surface band patterns are also discussed.
\end{abstract}

Key words: age, growth, histology, Rajidae, rays, vertebrae

\section{Introduction}

In the majority of ray species (family Rajidae), caudal thorns are found securely embedded in the caudal tissue overlying the spinal column, and to a lesser extent on other parts of the dorsal surface on certain species. It is probable that they have a defensive function, and may also assist in the emergence from the egg case (Clark, 1922). The surface bands of caudal thorns from bathyrajids have previously been correlated with an annual cycle of vertebral band deposition (Gallagher and Nolan, 1999). For a structure to be used as a valid ageing tool, it is important to have an understanding of its growth and band formation processes (Cailliet, et al., 1983; Casselman, 1987). Despite the fact that it has recently been established that caudal thorns can be used as effective ageing tools (Gallagher and Nolan, 1999), it is currently unclear how growth bands form in caudal thorns, and how the surface sculpture relates to the underlying morphology. Furthermore bathyrajids are typically slow growing species (Gallagher and Nolan, 1999) and therefore difficulties have been encountered in resolving both worn bands near the thorn tip and tightly spaced bands towards the periphery (Gallagher, 2000). Sectioning of growth structures has previously been recommended for both vertebral centra and dorsal fin spines to help improve band resolution, particularly in slow growing elasmobranchs (Cailliet, 1990; Branstetter and Musick, 1994).

An increased understanding of thorn growth and band formation processes could yield further confidence that these structures can be used as valid ageing tools, and thus be used in the derivation of valuable life history data of this potentially vulnerable commercially exploited group (family Rajidae). This study aims to provide this by using a variety of sectioning techniques to investigate the structure and growth processes of caudal thorns from Bathyraja brachyurops a commercially important bathyrajid fished around the Falkland Islands, for which an ageing study using whole caudal thorns has been carried out previously (Gallagher and Nolan, 1999).

\section{Methods}

\section{Thorn growth versus somatic growth}

A total of 110 thorn samples of B. brachyurops collected for a previous study (Gallagher and Nolan, 1999) were used in this study. Whole thorns were measured $(\mathrm{mm})$ by drawing the outline of the thorn viewed under a dissecting microscope using a drawing tube attachment, and derived measurements were plotted against total body length $(\mathrm{cm})$ to assess their relationship.

\section{Structure of caudal thorns}

Gross structure of caudal thorns. Whole, air-dried caudal thorns of $B$. brachyurops collected for a previous study (Gallagher and Nolan, 1999) were re-examined to assess surface band patterns (Fig. 1). To enhance these bands, thorns were stained using a silver nitrate staining technique (Gallagher and Nolan, 1999) and were viewed under a dissecting microscope using reflected light.

Histological structure of caudal thorns. To assess the underlying growth band pattern of caudal thorns, a 
total of $20 \mathrm{~B}$. brachyurops specimens, representing the main size ranges of this species ( 5 specimens between $20-40 \mathrm{~cm}, 40-60 \mathrm{~cm}, 60-80 \mathrm{~cm}$ and $80-100 \mathrm{~cm}$ (total length)), were collected by scientific observers from commercial fishing vessels within the Falkland Islands' Interim Conservation zone (FICZ) in 1997 (Falkland Islands: $51.45^{\circ} \mathrm{S}, 59.30^{\circ} \mathrm{W}$ ). The first five caudal thorns, posterior to the first haemal arch of the vertebral column, were removed from each specimen. Tissue was removed from the thorn by immersing the segments in hot water (about $70-85^{\circ} \mathrm{C}$ ). Thorns were further cleaned in cold running water, and subsequently placed in a formalin $(10 \%)$ solution, buffered in seawater. Samples were packed and labelled, with all relevant details, and transported to the Zoology Department, Trinity College, Dublin, for further analysis.

Excess tissue was further trimmed off the formalin preserved caudal thorns. Thorns were decalcified in DeCal (Raymond Alam) for between 12 and $20 \mathrm{hrs}$ depending on thorn size, and subsequently stored in $70 \%$ ethanol. Decalcified thorns were embedded in Paramat wax (melting point $56-58^{\circ} \mathrm{C}$ ). Vertical transverse sections of between 10 and $15 \mu \mathrm{m}$ and $15 \mathrm{~mm}$ were made using a rotary microtome (Leitz), and were placed onto glass slides (Fig. 1). Sections were then stained for between 20 mins and $1 \mathrm{hr}$ in Harris's heamatoxylin. Stained sections were subsequently examined under a compound microscope $(\times 40)$ using transmitted light.

A total of 20 thorns were selected from the air-dried samples of $B$. brachyurops (Gallagher and Nolan, 1999) and were embedded in resin and vertical transverse sections $(90-120 \mu \mathrm{m})$ were produced. Sections were examined under a compound microscope $(\times 20-\times 40)$ using transmitted light.

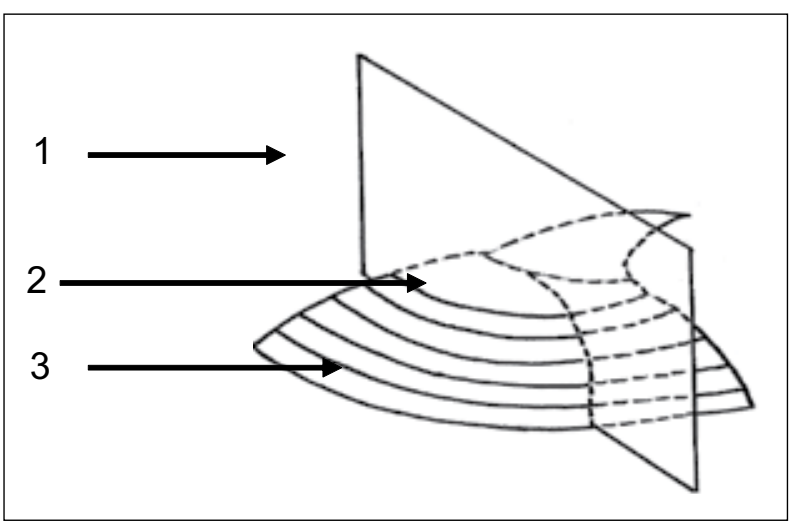

Fig. 1. Diagrammatic representation of a whole caudal thorn from Bathyraja brachyurops. Arrow 1, Plane of vertical transverse sectioning; Arrow 2, Base of proto-thorn; Arrow 3, Surface band.
Tetracycline incorporation. Thorns from a single tetracycline marked recaptured specimen from a Falkland Island ray-tagging program were examined. The specimen, which is currently being described (Bathyraja sp.), is a co-habitor, and morphologically similar to $B$. brachyurops. The recaptured specimen was an immature male, which was at liberty for 10 months (tagged 8 July 1994, recaptured 6 May 1995). Thorns were viewed under a dissecting microscope using ultra violet light.

\section{Results}

\section{Thorn growth versus somatic growth}

A logarithmic relationship between thorn size and total length was apparent for caudal thorns for each species (Fig. 2). For males this is described as $y=3.778 \ln (x)$ $7.230\left(r^{2}=0.810\right)$ and for females $y=3.733 \ln (x)-7.599$ $\left(r^{2}=0.723\right)$.

Whole thorns. Regularly spaced, concentric surface bands were readily evident on $B$. brachyurops thorns (Fig. $3)$. In larger specimens wear on the thorns was evident on occasion near the thorn apex, and surface bands were more tightly spaced nearer the distal margins. These however were not sufficient to reduce resolution.

Histological structure of caudal thorns. Histological and resin embedded (Fig. 4) vertical transverse sections displayed an internal 'inverted V-shaped' band morphology under the proto-thorn, with the base of each of these bands being externally expressed as a ridge on the thorn surface. Each new band was formed under the previously formed band, and therefore the innermost internal band represents the most recently formed.

Tetracycline incorporation. Tetracycline incorporation was readily apparent as a distinct intensely fluorescent

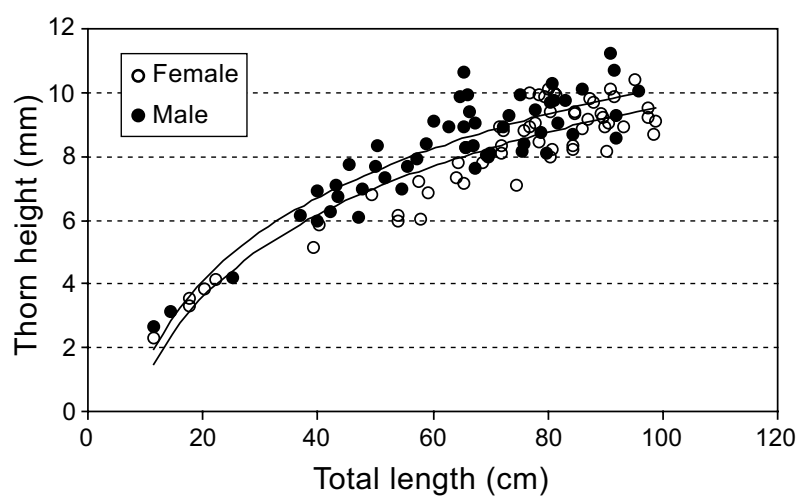

Fig. 2. The relationship between total length $(\mathrm{cm})$ and thorn height $(\mathrm{mm})$ for male $(\mathrm{N}=54)$ and female $(\mathrm{N}=56)$ Bathyraja brachyurops. 


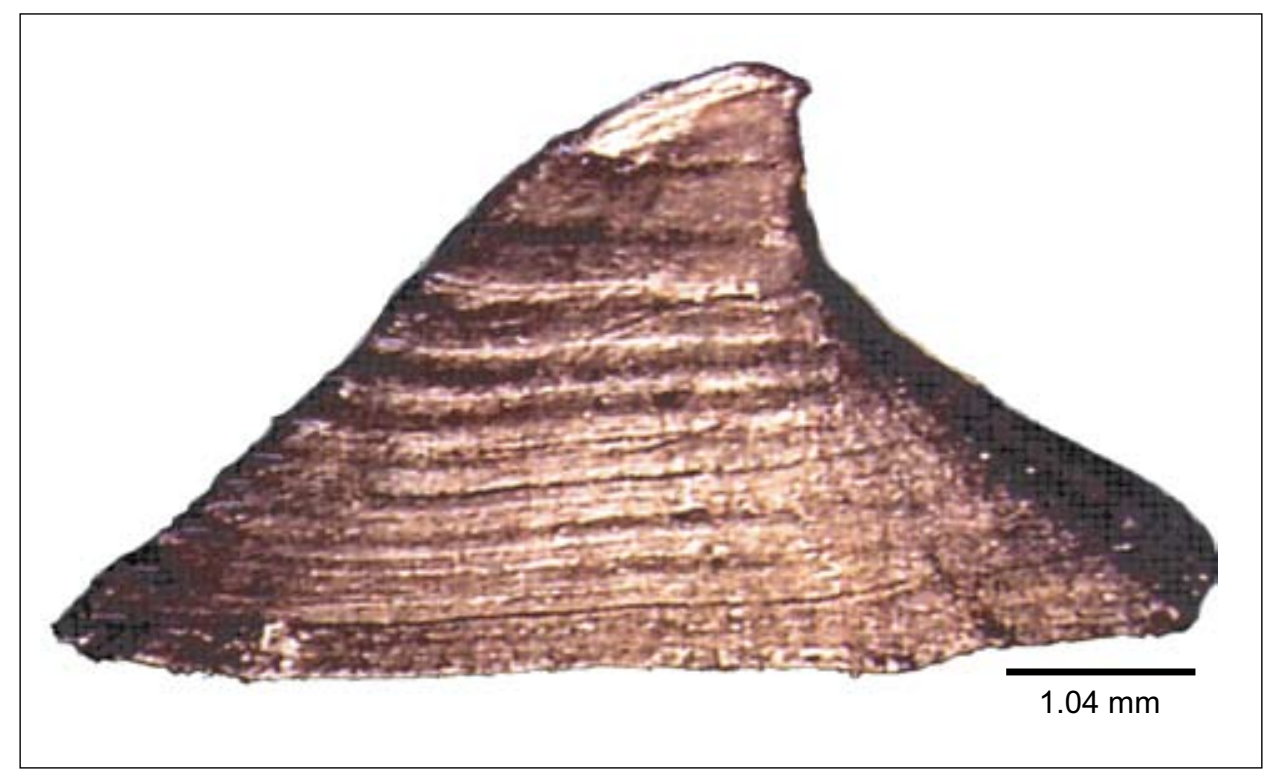

Fig. 3. Bathyraja brachyurops; photomicrograph of a whole silver nitrate stained caudal thorn (Scale bar $=1.04 \mathrm{~mm}$ ).
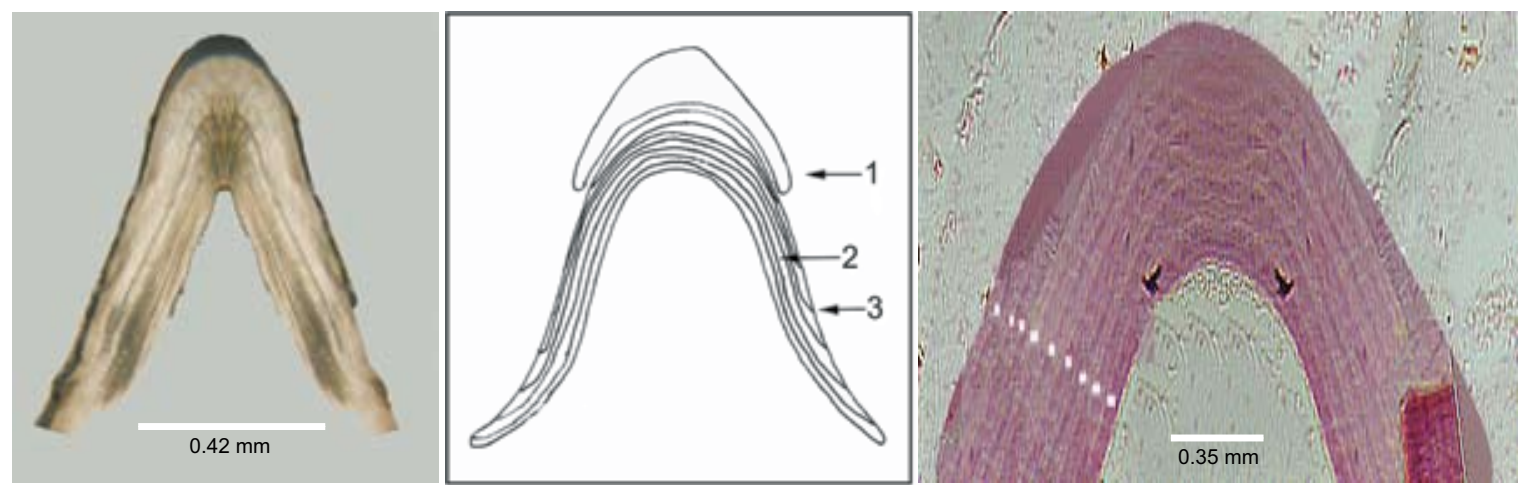

Fig. 4. Bathyraja brachyurops: Left; photomicrograph of a resin embedded caudal thorn in vertical transverse section. Scale bar $=0.42 \mathrm{~mm}$; Centre; Diagrammatic representation of a vertical transverse section of a caudal thorn from B. brachyurops, showing the relationship between the internal and surface band pattern. 1. Proto-thorn; 2 . Internal band; 3. Surface band; Right; photomicrograph of the apex of a decalcified caudal thorn in vertical transverse section, stained in haematoxylin and eosin. White bars denote internal band pattern. Scale bar $=0.35 \mathrm{~mm}$.

band on the distal margins of caudal thorns and was concurrent with ridge formation of surface bands in caudal thorns (Fig. 5).

\section{Discussion}

Caudal thorns are placoid scales in origin, and are formed from minerals deposited by epidermal and dermal cells. Placoid scales are typically composed of a vascular (supplied with blood) inner core of pulp, a middle layer of dentine and a hard enamel-like outer layer of vitrodentine (Helfman et al., 1997). Vertical transverse sections described in this study reveal the underlying band morphology under the proto-thorn as 'inverted $\mathrm{V}^{\prime}$ shaped bands. These internal bands form as successive cones, with the innermost bands under the tip representing the most recently formed, and the surface ridges on the caudal thorns being external expressions of each cone base. This band formation process is further corroborated in this study, as tetracycline from a specimen at liberty for under a year was incorporated into the most recently formed ridge near the distal margin of thorn. This growth 


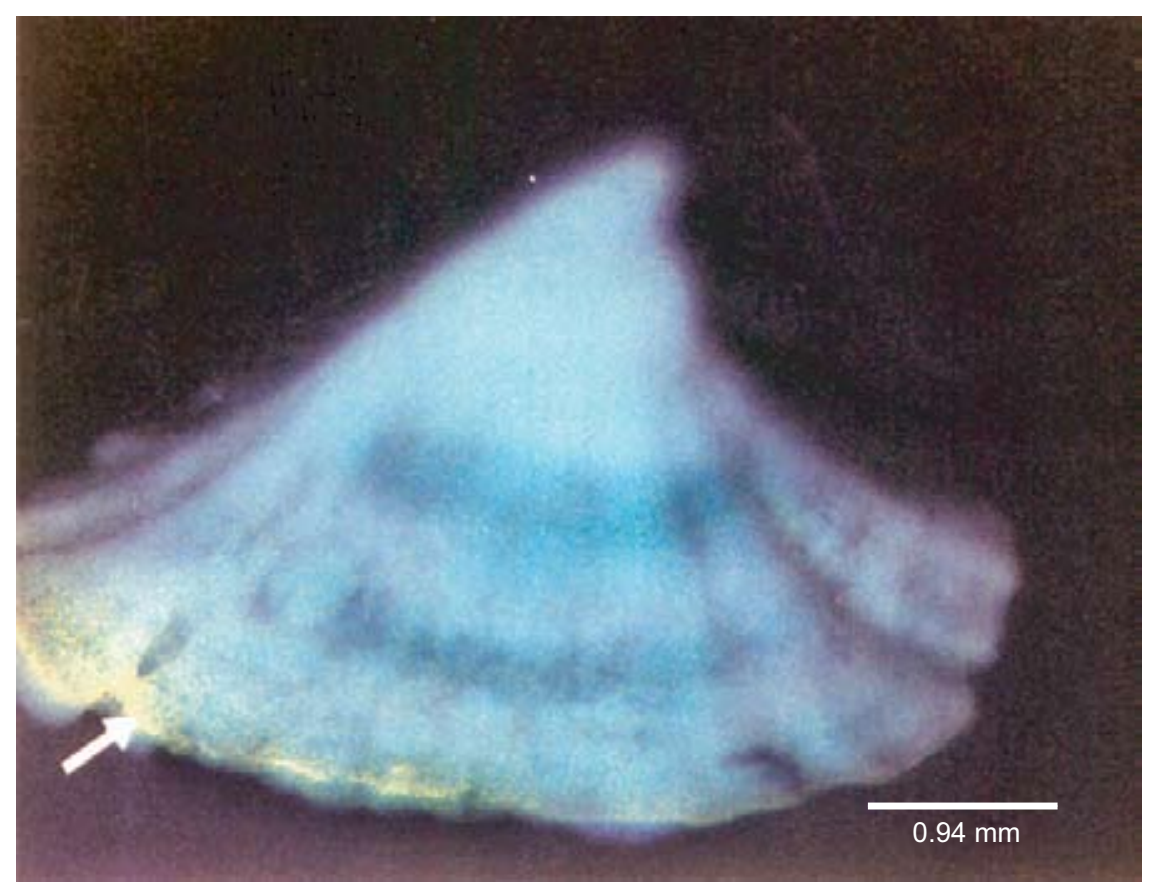

Fig. 5. Bathyraja sp.: photomicrograph of a whole unstained caudal thorn from a tetracycline tag-recaptured specimen $($ Scale bar $=0.94 \mathrm{~mm})$. White arrow denotes area of tetracycline incorporation.

and band formation process is somewhat analogous to that of dorsal fin spines on the spurdog, Squalus acanthias, which are also of placoid scale origin (Holden and Meadows, 1962; Beamish and McFarlane, 1987; McFarlane and Beamish, 1987).

It is probable that the surface ridges on the caudal thorns represent a near stasis in somatic growth, whereas the broader bands represent periods of more rapid growth. These processes are suggested because tetracycline was incorporated into a surface ridge in the recaptured specimen which was injected with tetracycline during the winter period (austral), when somatic growth would have been presumably slowest (Gallagher and Nolan, 1999). An important component of age and growth studies is the assurance that the structure being used to derive age presents a continuous record of growth (Casselman, 1983; Beamish and McFarlane, 1987). Casselman (1987, 1990) further suggested that in very large specimens of slow growing teleost species, structures that are involved in supporting mass such as vertebral centra continue to grow to support increasing body mass despite the fact that asymptotic length has been reached. They therefore give a better record of body growth than structures that cover the body, such as scales, which virtually cease growing as a species approaches its asymptotic length (Casselman, 1983). This near cessation in growth of scales in older fish has lead to gross inaccuracies in age assessments at older ages, where scales have been used exclusively as the primary ageing structure of slow growing teleost species (Beamish and McFarlane, 1987). There were initial concerns that as caudal thorns form on the body surface they may grow more slowly with increasing body size, and in consequence, may not accurately reflect the age of larger specimens. The logarithmic growth pattern between thorn and somatic growth evident from this study reveals that thorn growth does in fact slow relative to somatic growth. However, previous findings (Gallagher and Nolan, 1999) reveal that this reduction in thorn growth does not impact negatively on surface band resolution, as band resolution was higher on thorns than on vertebral centra for larger specimens of the majority species examined. An exception was however evident for larger specimens of female $B$. griseocauda, where resolution of bands on thorns relative to centra was generally lower (Gallagher and Nolan, 1999). It is probable that growth in this the largest species examined, slows dramatically, particularly in larger female specimens and therefore the distances between the surface bands and ridges become less apparent on the distal margins of caudal thorns, leading to reduced resolution. It is also probable that thorn wear near the tip, which was particularly evident in larger specimens of this species (Gallagher and Nolan, 1999), probably occluded the resolution of bands within this region. Similar wear 
on the dorsal fin spine of large specimens of the spurdog, Squalus acanthias has regularly been encountered, and has also led to reduced band counts (Ketchen, 1975; Soldat, 1982). The associated problems were overcome somewhat in ageing studies of this species, by measuring the diameter of the spine below the worn area, and estimating the number of bands in the worn area from a smaller specimen where spine wear was not evident (Soldat, 1982). This procedure could also be developed for caudal thorns from larger specimens of slow growing bathyrajid species (e.g. B. griseocauda). Vertical transverse sectioning, which was described in this study, and which is commonly used on the dorsal fin spines of the spurdog to increase resolution of bands for ageing purposes (Beamish and McFarlane, 1987), could also be carried out on caudal thorns for larger specimens of this and other species to ensure that the surface bands give an accurate account of the underlying band morphology.

Caudal thorns proved unsuccessful as an ageing tool for a number of other rays examined, namely four Irish species investigated by Gallagher (2000). Although a faint band pattern was discernible on distal margins of thorns from the thornback ray (Raja clavata), their resolution tended to be variable, and it could not be established if they were formed in a temporally predictable manner. For the other three species no band pattern could be resolved. It is unlikely that the thorn structures and growth processes for the Irish species examined are any different to those of the Falkland Islands species. The lack of surface bands, however, may be due to the fact that the cessation in somatic growth, which most likely causes the ridgedefined band pattern on caudal thorns from the slower growing deeper water Falkland Islands species (Gallagher, 2000), is not sufficiently abrupt to cause surface ridge formation in the faster growing temperate Irish species (Gallagher et al., 2004). Further research into the cellular structure of caudal thorns is warranted to ascertain how the thorn ultra structure changes with different stages of somatic growth.

This study does however provide an initial insight into the underlying structure and band formation process of this relatively novel and potentially useful ageing tool.

\section{References}

BEAMISH, R. J., and G. A. McFARLANE. 1987. Current trends in age determination methodology. In: The Age and Growth of Fish. R. C. Summerfelt and G. E. Hall (eds.). The Iowa State University Press, Ames, Iowa, p. 15-42.

BRANSTETTER, S., and J. A. MUSICK. 1994. Age and Growth Estimates for the Sand Tiger in the Northwestern Atlantic Ocean. Trans. Am. Fish. Soc., 123: 242-254.
CAILLIET, G. M. 1990. Elasmobranch age determination and verification: An updated review. In: Elasmobranchs as living resources: Advances in the biology, ecology, systematics and the status of the fisheries. H. L. Pratt, S. H. Gruber and T. Taniuchi (eds.). US Department of Commerce, Washington, 90:157-165.

CAILLIET, G. M., L. K. MARTIN, D. KUSHER, and P. WOLF. 1983. Techniques for enhancing vertebral bands in age estimation of California elasmobranchs. In: Proceedings of the International Workshop on Age Determination of Oceanic Pelagic Fishes: Tunas, Billfishes, and Sharks. E. D. Prince and L. M. Pulos (eds.). NOAA Tech. Rep., No. NMFS 8: $157-165$.

CASSELMAN, J. M. 1983. Age and growth assessment of fish from their calcified tissue-techniques and tools. In: Proceedings of the International Workshop on Age determination of Oceanic Pelagic Fishes: Tunas, Billfishes and Sharks. E. D. Prince and L. M. Pulos (eds.). US Department of Commerce, Washington. NOAA Tech. Rep., No. NMFS 8: 157-166.

CASSELMAN, J. M. 1987. Determination of age and growth. In: The biology of fish growth. S. Gill (ed.). Academic Press, London, London.

CASSELMAN, J. M. 1990. Growth and Relative Size of Calcified Structures of Fish. Trans. Am. Fish. Soc., 119: 673-688.

CLARK, R. S. 1922. Rays and Skates (Raiae) No. 1: Egg capsules and young. J. Mar. Biol. Assoc. UK, 12: 577-643.

GALLAGHER, M. J. 2000. The fisheries biology of commercial ray species from two geographically distinct regions. Ph.D. Thesis, Department of Zoology, University of Dublin, Trinity College, Dublin 2, Ireland.

GALLAGHER, M., and C. P. NOLAN. 1999. A novel method for the estimation of age and growth in rajids using caudal thorns. Can. J. Fish. Aquat. Sci., 56: 1590-1599.

GALLAGHER, M. J., C. P., NOLAN, and F. JEAL. 2004. Age, growth and maturity of the commercial ray species from the Irish Sea. Presented at the Symposium Elasmobranch Fisheries: Managing for sustainable use and biodiversity conservation. J. Northw. Atl. Fish. Sci., 35: 47-66 (this volume).

HELFMAN, G. S., B. B COLLETTE, and D.E. FACEY 1997. The Diversity of Fishes. Blackwell Science Main St, Malden, MA 02148, $528 \mathrm{p}$.

HOLDEN, M. J., and P. S. MEADOWS. 1962. The structure of the spine of the Spur Dogfish (Squalus acanthias L.) and its use for age determination. J. Mar. Biol. Assoc. UK, 42: 179-197.

KETCHEN, K. S. 1975. Age and growth of dogfish Squalus acanthias in British Columbia Waters. J. Fish. Res. Board Can., 32: 43-59.

McFARLANE, G. A., and R. J. BEAMISH. 1987. Validation of the dorsal spine method of age determination for spiny dogfish. In: The Age and Growth of Fish. R. C. Summerfelt and G. E. Hall (eds.). The Iowa State University Press, Ames, Iowa, p. 287-300.

SOLDAT, V. T. 1982. Age and size of spiny dogfish, Squalus acanthias, in the Northwest Atlantic. NAFO Sci. Coun. Studies, 3: 47-52. 
